\title{
EDITORIAL
}

\section{Special issues in pediatric deceased organ donation}

\author{
Matthew J. Weiss ${ }^{1,2,3,4,5,6^{*}}$ (0), Alicia Pérez Blanco ${ }^{7,8}$ and Ben Gelbart9,10,11
}

๑ 2019 Springer-Verlag GmbH Germany, part of Springer Nature

\section{Introduction}

Deceased donation from a child is always preceded by tragedy. The death of a child goes against biology and culture, and leaves parents emotionally defenseless, and healthcare workers are forced to confront the death of a child in their care. These emotional factors, combined with unfamiliarity with pediatric physiology, can create an impression that pediatric donation is so difficult that it should only be considered in very rare circumstances. However, there are many similarities with adult practice. Children of all ages donate solid organs through donation after brain death (DBD) and donation after circulatory determination of death (DCD) pathways.

\section{Epidemiology}

International practice in pediatric donation is difficult to compare as there are currently no broadly accepted standards for reporting of pediatric donation data. A recent survey of the UK, Spain, and the USA showed that overall pediatric donation rates (in under 18-year-olds) were substantially lower than for adults (details in supplementary material) [1]. Pediatric DCD (pDCD) represented $2.6-32.2 \%$ of total pediatric donation, and most organs recovered from pediatric patients were allocated to adults, similar to previous reports $[1,2]$.

Identification, approach, and consent for donation Analysis of available pediatric identification and referral data suggest missed donation opportunities. A large US center recently found that clinicians failed to refer patients to the local donation organization in $23 \%$ of

\footnotetext{
*Correspondence: matthew-john.weiss@chudequebec.ca

${ }^{1}$ Division of Pediatric Intensive Care, Centre-Mère Enfant Soleil du CHU de Québec, Quebec, Canada
}

Full author information is available at the end of the article withdrawal of therapy cases, with a non-referral rate of $39 \%$ for children aged 1 week to 1 month [3]. A report from the UK identified many contributory factors to their missed referral opportunities, including perceived medical unsuitability, and unclear disease processes leading to death [4]. As referral for consideration of donation is the critical first step in the donation process, most organ donation organizations encourage clinicians to refer all children with either neurologic injury that may proceed to brain death or after a decision to withdrawal life-sustaining therapy has been made, regardless of the bedside clinician's perception of donation eligibility [5].

Once referred, the approach for discussion of donation with the family or surrogate must be carefully planned and performed sensitively. While difficult in actual practice, the goal of the initial approach should be to decouple discussion of donation from delivery of prognostic news. Adequate time should be given for parents to consider their options and the person discussing donation should have a detailed understanding of the donation process. Spanish data suggest that professionals with specialized training present for approach and consent discussions are associated with higher consent rates [6], but these findings are not specific to pediatric patients. Families should never be pressured into a decision, but since families often experience donation as an opportunity to create a lasting legacy after the loss of their loved one, every family should be given the option to autonomously decide if they wish to pursue donation [7].

Parental or surrogate consent-referred to as authorization in some jurisdictions-for pediatric donation has some distinctions from consent given by surrogates in adult donation. Most children have never expressed an opinion on donation and would not be considered competent if they had. Also, since donation does not convey medical benefit to the donor, it cannot comply with a purely medically based definition of best interests for

\section{6 Springer}


the child, and parental consent recognizes authority to make decisions based on family values, not simply medical benefit. Parental consent authority encompasses the values and welfare of the whole family in a model of family-centered best interests, underpinned by their intimate knowledge of family needs [7].

\section{Pediatric determination of brain death}

Most guidelines and legislation on brain death in children, including term neonates, recommend that clinical examination is paramount [8-10]. With decreasing age, however, increased caution must be applied, due to immaturity of brain stem reflexes and open fontanelles that alter brainstem herniation patterns. Generally, this leads to recommendations for longer wait times between exams and more ancillary tests. For example, in neonates many organizations recommend waiting at least $24 \mathrm{~h}$ between exams, in contrast to simultaneous exams accepted in older children and adults [8-10]. For all age groups, there is substantial international variability in which ancillary tests are recommended and when they should be applied (Table 1).

\section{Donor management after brain death}

Brain death in children elicits a neurohumoral and inflammatory response that can lead to hemodynamic instability, temperature dysregulation, and diabetes insipidus [11]. The goals of therapy are preservation of physiologic homeostasis and require expert care in a pediatric intensive care unit (PICU). While most treatments resemble routine PICU care, some therapies are recommended specifically for the pediatric DBD population, including hormonal replacement therapies, typically steroids, vasopressin, and thyroid hormone [11]. The use of vasopressin as a first-line agent for hemodynamic instability with evidence of diabetes insipidus is often recommended. Donor hypothermia has shown promise in adult kidney transplantation [12], but effects in pediatric donors are unknown.

\section{Pediatric donation after circulatory determination of death}

While there has been resistance from a minority of authors to pDCD based on ethical concerns, the current broad professional consensus is that pDCD can be ethically practiced in a manner very similar to adults [13].

Table 1 International variability in ancillary test recommendations

\begin{tabular}{|c|c|c|}
\hline Country & $\begin{array}{l}\text { Situation where ancillary tests are recommended by national } \\
\text { guidelines }\end{array}$ & Accepted ancillary tests \\
\hline Australia (11) & $\begin{array}{l}\text { All neonates less than } 36 \text { weeks gestation } \\
\text { When clinical examination cannot be relied upon or safely per- } \\
\text { formed } \\
\text { If preconditions cannot be met }\end{array}$ & $\begin{array}{l}\text { Four-vessel cerebral arterial angiography; radionuclide CBF; } \\
\text { CTA (only if angiography and radionuclide tests are not possible) } \\
\text { MRI and TCD not recommended }\end{array}$ \\
\hline Canada (9) & $\begin{array}{l}\text { When aspects of the clinical exam cannot be completed in a } \\
\text { patient in a deep unresponsive coma and in the absence of } \\
\text { reversible conditions that can mimic brain death }\end{array}$ & $\begin{array}{l}\text { Four-vessel cerebral arterial angiography; radionuclide CBF } \\
\text { EEG specifically not recommended }\end{array}$ \\
\hline Israel (19) & All patients & $\begin{array}{l}\text { CTA; TCD; auditory brain stem evoked potentials; HMPAO-SPECT; } \\
\text { radionuclide CBF }\end{array}$ \\
\hline Italy (20) & $\begin{array}{l}\text { 6-h EEG for patients of all ages } \\
\text { Testing to confirm absence of cerebral blood flow required for } \\
\text { patients under } 1 \text { year }\end{array}$ & Four-vessel cerebral arterial angiography; TCD \\
\hline Spain (12) & $\begin{array}{l}\text { Any age when preconditions cannot be met, or clinical examina- } \\
\text { tion cannot be fulfilled, or exam cannot be repeated according to } \\
\text { law observational time } \\
\text { Required for neonates less than } 37 \text { weeks gestation }\end{array}$ & $\begin{array}{l}\text { Four-vessel cerebral arterial angiography; EEG; CT angiogram; } \\
\text { auditory brain stem evoked potentials; HMPAO-SPECT }\end{array}$ \\
\hline USA (10) & $\begin{array}{l}\text { Recommended when (1) components of the examination or apnea } \\
\text { testing cannot be completed safely; ( } 2 \text { ) if there is uncertainty } \\
\text { about the results of the neurologic examination; or ( } 3 \text { ) if a medi- } \\
\text { cation effect may interfere with evaluation of the patient } \\
\text { Can be used to assist the clinician in making the diagnosis of brain } \\
\text { death to reduce the observation period }\end{array}$ & Four-vessel cerebral arterial angiography; EEG; radionuclide CBF \\
\hline
\end{tabular}

CBF cerebral blood flow, CTA computed tomography angiography, EEG electroencephalogram, HMPAO-SPECT hexamethylpropylene amine oxime single photon emission computed tomography, TCD transcranial Doppler

Ministerio de Sanidad SSEl. Boletín Oficial del Estado, Real Decreto 1723/2012 [Official bulletin of the Spanish Health Ministry, Decree 1723/2012] (2012).https://www. boe.es/buscar/pdf/2012/BOE-A-2012-15715-consolidado.pdf. Accessed Dec 2018

Cohen J, Ashkenazi T, Katvan E, Singer P (2012) Brain death determination in Israel: the first 2 years experience following changes to the brain death law-opportunities and challenges. Am J Transpl 12(9):2514-2518

Vicenzini E, Pro S, Pulitano P, Rocco M, Spadetta G, Zarabla A et al (2013) Current practice of brain death determination and use of confirmatory tests in an Italian university hospital: a report of 66 cases. Minerva Anestesiol 79(5):485-491 
DCD kidneys have been recovered from neonates as small as $1.9 \mathrm{~kg}$, and pDCD liver, lung, and pancreas donations with favorable outcomes are well described [13]. Standardization of practice remains difficult with few national or international guidelines [14], though national guidelines specific to pDCD have been developed [15].

\section{Emerging challenges and conclusion}

The field of pediatric donation needs more and betterquality research to inform practice. Standardized sharing of practices and outcomes using agreed definitions is necessary. Knowledge of the impact of the donation process on families is lacking, and the best ways to educate healthcare providers and the general public on donation issues are unknown. Novel techniques such as normothermic regional perfusion and cardiac DCD are being practiced in adult populations and may represent a means of increasing the number and quality of organs for transplantation. Neonatal donation is also continually evolving. While DBD is a rare event in this population, methods to increase utilization of potential neonatal donors include increased pDCD en bloc kidney transplantation, liver cell transfusion, and the consideration of anencephalic infants for potential donation.

More knowledge in the field will allow clinicians to ensure that all family wishes to donate are honored and that more patients on transplant waiting lists receive lifesaving transplants.

\section{Electronic supplementary material}

The online version of this article (https://doi.org/10.1007/s00134-019-05523-2) contains supplementary material, which is available to authorized users.

\begin{abstract}
Author details
${ }_{1}^{1}$ Division of Pediatric Intensive Care, Centre-Mère Enfant Soleil du CHU de Québec, Quebec, Canada. ${ }^{2}$ Department of Pediatrics, Université Laval, Faculté de Médecine, Quebec, Canada. ${ }^{3} \mathrm{CHU}$ de Québec-Université Laval Research Center, Population Health and Optimal Health Practices Research Unit, Traumatology-Emergency-Critical Care Medicine, Université Laval, Quebec, Canada. ${ }^{4}$ Medical Director of Deceased Donation, Transplant Québec, Montreal, Canada. ${ }^{5}$ Canadian Donation and Transplant Research Program, Edmonton, Canada. ${ }^{6}$ Deceased Donation, Canadian Blood Services, Ottawa, Canada. ${ }^{7}$ Division of Intensive Care, Hospital de La Princesa, Madrid, Spain. ${ }^{8}$ National Transplant Organisation (ONT), Madrid, Spain. ${ }^{9}$ Department of Paediatrics, University of Melbourne, Melbourne, Australia. ${ }^{10}$ Intensive Care Unit, Royal Children's Hospital, Melbourne, Australia. ${ }^{11}$ Murdoch Children's Research Institute, Melbourne, Australia.
\end{abstract}

\section{Acknowledgements}

Special thanks to Sam Shemie for participation in the planning of this manuscript and his mentorship over the years.

\section{Funding}

None of the authors have financial interests with for-profit entities. All authors have received funding from governmental agencies for administration of organ donation activities or research in organ donation.

\section{Compliance with Ethical Standards}

Ethical approval

An approval by an ethics committee was not applicable.

\section{Publisher's Note}

Springer Nature remains neutral with regard to jurisdictional claims in published maps and institutional affiliations.

Received: 10 November 2018 Accepted: 6 January 2019

Published online: 6 February 2019

\section{References}

1. Weiss MJ, Dominguez-Gil B, Lahaie N, Nakagawa TA, Scales A, Hornby L (2019) Development of a multinational registry of pediatric deceased organ donation activity. Pediatr Transplant. https://doi.org/10.1111/ petr.13345

2. Workman JK, Myrick CW, Meyers RL, Bratton SL, Nakagawa TA (2013) Pediatric organ donation and transplantation. Pediatrics 131(6):e1723-e1730

3. Bennett EE, Sweney J, Aguayo C, Myrick C, Antommaria AHM, Bratton SL (2015) Pediatric organ donation potential at a children's hospital. Pediatr Crit Care Med 16(9):814-820

4. Hawkins KC, Scales A, Murphy P, Madden S, Brierley J (2018) Current status of paediatric and neonatal organ donation in the UK. Arch Dis Child 103(3):210-215

5. Domínguez-Gil B, Murphy P, Procaccio F (2015) Ten changes that could improve organ donation in the intensive care unit. Intensive Care Med 42(2):264-267

6. Domínguez-Gil B, Coll E, Elizalde J, Herrero JE, Pont T, Quindós B et al (2017) Expanding the donor pool through intensive care to facilitate organ donation: results of a Spanish multicenter study. Transplantation 101(8):e265-e272

7. United Kingdom Donation Ethics Committee (UKDEC) (2015) Ethical issues in paediatric organ donation - a position paper. https://www. aomrc.org.uk/wp-content/uploads/2016/04/Paediatric_organ_donat ion_position_0615-2.pdf. Accessed Nov 2018

8. Shemie SD, Doig C, Dickens B, Byrne P, Wheelock B, Rocker G et al (2006) Severe brain injury to neurological determination of death: Canadian forum recommendations. CMAJ 174:S1-S13

9. Nakagawa TA, Ashwal S, Mathur M, Mysore M, Society of Critical Care Medicine, Section on Critical Care and Section on Neurology of American Academy of Pediatrics, Child Neurology Society (2011) Clinical reportguidelines for the determination of brain death in infants and children: an update of the 1987 task force recommendations. Crit Care Med 128:e720-e740

10. Silvester W, Dobb GJ, Judson J, Millar J, Moodie S, Opdam H et al (2017) The ANZICS statement on death and organ donation. https://www.clini calguidelines.gov.au/portal/2487/anzics-statement-death-and-organ -donation-edition-32. Accessed Dec 2018

11. Kotloff RM, Blosser S, Fulda GJ, Malinoski D, Ahya VN, Angel L et al (2015) Management of the potential organ donor in the ICU. Crit Care Med 43(6):1291-1325

12. Niemann CU, Feiner J, Swain S, Bunting S, Friedman M, Crutchfield M et al (2015) Therapeutic hypothermia in deceased organ donors and kidneygraft function. N Engl J Med 373(27):2687

13. Weiss MJ, Hornby L, Witteman W, Shemie SD (2016) Pediatric donation after circulatory determination of death. Pediatr Crit Care Med 17(3):e88-e108

14. Vileito A, Siebelink MJ, Verhagen A (2018) Literature overview highlights lack of paediatric donation protocols but identifies common themes that could guide their development. Acta Paediatr 107(5):744-752

15. Weiss MJ, Hornby L, Rochwerg B, van Manen M, Dhanani S, Sivarajan VB et al (2017) Canadian guidelines for controlled pediatric donation after circulatory determination of death—summary report. Pediatr Crit Care Med 18(11):1035-1046 